\title{
Examining legalism, scrupulosity, family perfectionism, and psychological adjustment among LDS individuals
}

\author{
Kawika Allen \\ Brigham Young University, gekawika_allen@byu.edu \\ Kenneth T. Wang \\ Fuller Theological Seminary \\ Hannah Stokes \\ Brigham Young University
}

Follow this and additional works at: https://scholarsarchive.byu.edu/facpub

Part of the Mental and Social Health Commons

\section{Original Publication Citation}

G.E. Kawika Allen, Kenneth T. Wang \& Hannah Stokes (2015): Examining legalism, scrupulosity, family perfectionism, and psychological adjustment among LDS individuals, Mental Health, Religion \& Culture, DOI: 10.1080/13674676.2015.1021312

\section{BYU ScholarsArchive Citation}

Allen, Kawika; Wang, Kenneth T.; and Stokes, Hannah, "Examining legalism, scrupulosity, family perfectionism, and psychological adjustment among LDS individuals" (2015). Faculty Publications. 3169. https://scholarsarchive.byu.edu/facpub/3169 
This article was downloaded by: [BYU Brigham Young University], [G. E. Kawika Allen] On: 30 March 2015, At: 13:26

Publisher: Routledge

Informa Ltd Registered in England and Wales Registered Number: 1072954 Registered office: Mortimer House, 37-41 Mortimer Street, London W1T 3J H, UK

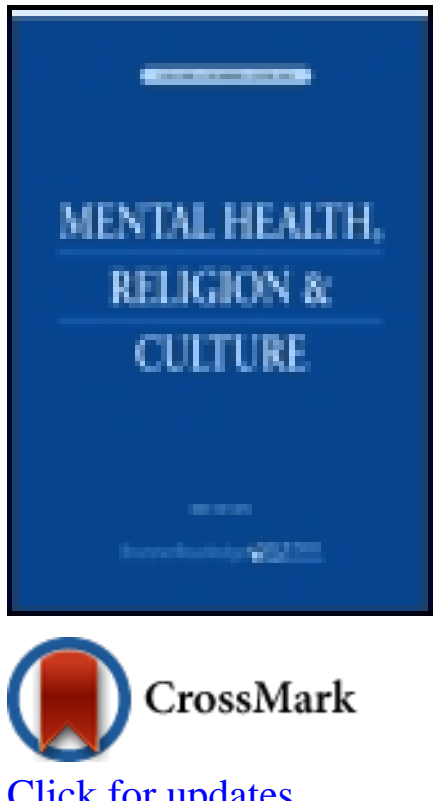

Click for updates

\section{Mental Health, Religion \& Culture}

Publication details, including instructions for authors and subscription information:

http:/ / www.tandfonline.com/loi/ cmhr20

\section{Examining legalism, scrupulosity, family perfectionism, and psychological adj ustment among LDS individuals}

\author{
G. E. Kawika Allen ${ }^{a}$, Kenneth T. Wang ${ }^{b} \&$ Hannah Stokes ${ }^{c}$ \\ a Department of Counseling Psychology and Special Education, \\ Brigham Young University, 273 MCKB, Provo, UT 84602, USA \\ ${ }^{b}$ Department of Psychology, Fuller Theological Seminary, 135 \\ North Oakland Avenue, Pasadena, CA 91101, USA \\ c Department of Counseling Psychology and Special Education, \\ Brigham Young University, 340 MCKB, Provo, UT 84602, USA \\ Published online: 26 Mar 2015.
}

To cite this article: G.E. Kawika Allen, Kenneth T. Wang \& Hannah Stokes (2015): Examining legalism, scrupulosity, family perfectionism, and psychological adj ustment among LDS individuals, Mental Health, Religion \& Culture, DOI: 10.1080/ 13674676.2015.1021312

To link to this article: http:// dx. doi.org/ 10.1080/ 13674676. 2015. 1021312

\section{PLEASE SCROLL DOWN FOR ARTICLE}

Taylor \& Francis makes every effort to ensure the accuracy of all the information (the "Content") contained in the publications on our platform. However, Taylor \& Francis, our agents, and our licensors make no representations or warranties whatsoever as to the accuracy, completeness, or suitability for any purpose of the Content. Any opinions and views expressed in this publication are the opinions and views of the authors, and are not the views of or endorsed by Taylor \& Francis. The accuracy of the Content should not be relied upon and should be independently verified with primary sources of information. Taylor and Francis shall not be liable for any losses, actions, claims, proceedings, demands, costs, expenses, damages, and other liabilities whatsoever or howsoever caused arising directly or indirectly in connection with, in relation to or arising out of the use of the Content.

This article may be used for research, teaching, and private study purposes. Any substantial or systematic reproduction, redistribution, reselling, loan, sub-licensing, systematic supply, or distribution in any form to anyone is expressly forbidden. Terms \& 
Conditions of access and use can be found at http://www.tandfonline.com/page/termsand-conditions 


\title{
Examining legalism, scrupulosity, family perfectionism, and psychological adjustment among LDS individuals
}

\author{
G.E. Kawika Allen ${ }^{a *}$, Kenneth T. Wang ${ }^{\mathrm{b}}$ and Hannah Stokes ${ }^{\mathrm{c}}$ \\ ${ }^{a}$ Department of Counseling Psychology and Special Education, Brigham Young University, 273 MCKB, \\ Provo, UT 84602, USA; ${ }^{b}$ Department of Psychology, Fuller Theological Seminary, 135 North Oakland \\ Avenue, Pasadena, CA 91101, USA; ' Department of Counseling Psychology and Special Education, \\ Brigham Young University, 340 MCKB, Provo, UT 84602, USA
}

(Received 16 January 2015; accepted 17 February 2015)

\begin{abstract}
This study examined the relationships and interactions between legalism, scrupulosity, family perfectionism, guilt, and shame among 421 Latter-Day Saints (LDS or Mormons). The results showed that scrupulosity fully mediated the links between legalism and guilt, as well as legalism and shame. A moderated-mediation effect was found, in which family discrepancy (maladaptive perfectionism) intensified the scrupulosity-shame association in the mediation model of legalism and shame by scrupulosity. Family discrepancy was not a significant moderator for the mediation model of legalism and guilt by scrupulosity. Additional results are provided and implications of these findings are outlined.
\end{abstract}

Keywords: religiosity; perfectionism; scrupulosity; guilt; shame; Latter-Day Saints

Religiousness linked to psychological processes has attracted a significant amount of research in the USA (Allen \& Heppner, 2011; Allen \& Wang, 2014; Richards \& Bergin, 2005). Many individuals who self-identify as religious use spiritual strategies in coping with psychological difficulties, including depression, anxiety, stress, and interpersonal struggles (Allen \& Heppner, 2011; Richards \& Bergin, 2005). A considerable majority of these individuals turn first to God as a frontline defence when facing mental illness (Allen \& Heppner, 2011). Spiritual strategies such as meditation, prayer, fasting, studying religious text, interacting and socialising with others from the congregation for emotional support, as well as speaking with religious leaders or pastors could be therapeutic for religious individuals. Thus, integrating religious aspects in psychotherapy could be beneficial for some clients (Post \& Wade, 2009; Richards \& Bergin, 2005). Specifically, an issue that may arise among highly religious individuals in psychotherapy could be interpreting the religious doctrine and aligning their beliefs and behaviours with that doctrine. For example, many Christian denominations teach the concept of grace and its role in helping their congregations to live a spiritual life. However, many religious individuals may not understand how God's grace is defined and used to buffer against emotional difficulties. Christian denominations differ when teaching about grace and may merit a closer examination of this concept as it relates to psychological outcomes. One of these Christian faiths that is often misunderstood by

*Corresponding author. Email: gekawika_allen@byu.edu 
other religious groups and society as a whole is The Church of Jesus Christ of Latter-Day Saints (LDS; also known as Mormons).

\section{Grace and legalism}

According to Bassett (2013), grace is the understanding and ability to feel God's unconditional love intrinsically without losing a sense of the seriousness of one's undesirable behaviour or sin. Other scholars would contend that grace also includes corrective work by the individual, but it is likewise accompanied by feeling the love of God (Watson, Chen, \& Sisemore, 2011). On the opposite end of grace is legalism, believing in the necessity to earn or work towards receiving God's love and acceptance (Bassett, 2013). Specifically, a definition of legalism (Bassett, 2013) can be described as a strict belief and overemphasis on conduct through specific works for God's approval and acceptance, and the lack of understanding and knowledge of accepting the grace of God towards the achievement of salvation.

Research suggests that those who score higher on belief of God's grace given freely without legalism showed lower levels of depression and anxiety and higher levels of self-compassion (Bassett, 2013). Thus, as a potential religious coping strategy for psychological difficulties, the concept of grace can be emphasised to lessen emotional strain. However, little is empirically known about the influence of legalism on one's well-being. Therefore, of particular interest in this study is examining how LDS members apply the concept of legalism, which may be linked to psychological adjustment. Some recent studies have looked at psychological well-being, adjustment, and outcomes among LDS people (Allen \& Heppner, 2011; Allen \& Wang, 2014), but virtually nothing has been documented on the psychological impact of legalism. Therefore, it was important to know whether legalism in an LDS context may be associated with psychological adjustment. Along with investigating legalism, guilt and shame were also of interest in this study.

\section{Shame and guilt}

Guilt and shame have been associated with one's tendency to accept forgiveness (Konstam, Chernoff, \& Deveney, 2001). The two are classified by researchers as separate emotions: shame focusing on oneself as a person, and guilt focusing on one's actions (Fedewa, Burns, \& Gomez, 2005). Defining shame and guilt accurately and separately is particularly important when examining these constructs among religious individuals, as shame may be associated with heightened long-term psychological struggles (i.e., hopelessness and worthlessness), while guilt is more time-limited to disappointment and regret for particular inappropriate behaviours (perhaps perceived as being sinful). Previous research has been done among this religious group related to shame and guilt in which LDS women reported higher levels of guilt compared to LDS men (Richards, Smith, \& Davis, 1989). However, this research was done over 25 years ago; thus, examining guilt currently among LDS men and women is vital to examine whether any differences could be present regarding gender.

\section{Scrupulosity}

Scrupulosity, which involves pervasive concerns about what one perceives as sinful activity along with compulsions to participate in repetitive religious acts (Abramowitz, Huppert, Cohen, Tolin, \& Cahill, 2002), is also found among some religious LDS individuals (Allen \& Wang, 2014). Research by Cefalu (2010) purport that those who hold legalistic views tend to stress the importance of perfectly following moral laws, which could exhibit forms of scrupulosity. Other studies on religious scrupulosity (Antony, Downie, \& Swinson, 1998; Foa, Abramowitz, Franklin, \& Kozak, 1999; Nelson, Abramowitz, Whiteside, \& Deacon, 2006) have found a persistent 
pattern of fear concerning sin and urges to perform excessive religious behaviours, similar to obsessive-compulsive disorder. Research on this type of scrupulosity among LDS individuals (Allen \& Wang, 2014) related to fears of sin and punishment from God have found that scrupulosity was linked to higher levels of anxiety. In addition, studies about religious people have shown that scrupulosity is associated with shame and guilt (Ciarrocchi, 1995; Fergus \& Valentiner, 2012; Miller \& Hedges, 2008), which may be linked to well-being. Building from previous research by Allen and Wang (2014) who examined the mediating effects of scrupulosity related to psychological adjustment among LDS individuals, the authors also chose to include scrupulosity in this sample of LDS individuals to examine the associations among scrupulosity, legalism, guilt, and shame, as well as potential mediating effects of scrupulosity between legalism and guilt or shame. Exercising specific behaviours religiously through legalism (the need to receive God's acceptance through works) could be associated with religious scrupulosity by way of repetitive, compulsive (perhaps maladaptive) behaviours, resulting towards the need to be in good conscience with God. Therefore, the authors were interested in knowing if legalism may be associated with guilt and shame through scrupulosity among this LDS sample. Another variable that could be correlated among these is perfectionism.

\section{Perfectionism}

Perfectionism is multidimensional with both adaptive and maladaptive aspects (Stoeber \& Otto, 2006). Discrepancy (the feeling that one is never good enough) is one of the defining features of maladaptive perfectionism, which has been associated with guilt and shame (e.g., Fedewa et al., 2005; Rice \& Slaney, 2002). Conversely, adaptive perfectionism is characterised by having high standards, but not being necessarily troubled when the standards are not met. Striving for high standards has been associated with higher self-esteem and life satisfaction (Allen \& Wang, 2014). Among LDS individuals, research has been documented related to maladaptive perfectionism (e.g., Allen \& Wang, 2014; Richards, Owen, \& Stein, 1993) reporting psychological relief when receiving psychotherapy interventions to alleviate symptoms of this type of perfectionism (Richards et al., 1993). However, much is still unknown about perfectionistic LDS people related to emotional outcomes such as shame and guilt.

In addition, perfectionism can also originate from different sources. One important source is the family, especially for individuals from collectivistic cultures/communities that place high value on the family. Wang (2010) argued for the importance of studying family perfectionism, the perception that family members are imposing perfectionistic standards or critical evaluations on the individual. Family perfectionism includes adaptive and maladaptive aspects that are parallel to personal perfectionism. Having higher family standards has been associated with higher self-esteem (Wang, 2010), and family discrepancy has been linked with depressive and anxiety symptoms (Ortega, Wang, Slaney, Hayes, \& Morales, 2014). In addition, family discrepancy has been linked to suicidal risks, serving as a moderator that intensifies the positive associations between interpersonal risk factors (i.e., perceived burdensomeness and thwarted belongingness) and suicide ideation (Wang, Wong, \& Fu, 2013). Thus, this maladaptive form of perfectionism from one's family is an important factor to examine among LDS individuals who believe that family is at the core of its values. The authors were interested in understanding whether family discrepancy serves as a moderator of the relationship between scrupulosity and guilt and shame.

\section{Purpose of this study}

Building on a recent study by Allen and Wang (2014) examining related variables within a similar model, this study examined how legalism, scrupulosity, and family perfectionism are associated 
with shame and guilt among religious LDS individuals. Many members of the Church of Jesus Christ of LDS are highly religious (Allen \& Heppner, 2011; Allen \& Wang, 2014), and the importance of the family is a critical aspect of their doctrine and practice (Hinckley, 1995). The literature lacks information related to psychological adjustment among LDS families who may experience perfectionistic stress (Allen \& Wang, 2014; Wang, 2010). Investigating the association of these constructs with psychological adjustment among religious LDS families could not only increase our understanding of this issue among this population, but also guide mental health professionals to provide assistance to LDS clients (Allen \& Wang, 2014).

The study examined the following hypotheses:

\begin{abstract}
Hypothesis 1: LDS women will report significantly higher scores in religious commitment, guilt, and shame, as well as scrupulosity and family perfectionism than their counterparts;

Hypothesis 2: Scrupulosity will mediate the association between legalism and outcome variables; specifically, (2a) the positive association between legalism and shame, and (2b) the positive association between legalism and guilt;

Hypothesis 3: The mediation model specified in Hypothesis 2 will be moderated by family discrepancy; specifically, (3a) the link between scrupulosity and shame will be amplified by higher levels of family discrepancy, and (3b) the link between scrupulosity and guilt will be amplified by higher levels of family discrepancy (see Figure 1).
\end{abstract}

\title{
Methods
}

\section{Participants}

This study included 421 LDS individuals (211 women, 208 men, and two unspecified) living in the USA. The majority of the participants were White (87\%), ages ranged from 18 to 63 years, mean of 23 years. The participants were asked on a Likert scale how "active" they were in the LDS Church $(1=$ Not at all active in the LDS Church to $5=$ Very active in the LDS Church $)$. The term "active" is a common term in the LDS Church to describe the person's level of intrinsic and extrinsic commitment to the faith. Approximately $81 \%$ reported that they were "very active" and the remaining $19 \%$ indicated at least "active" in the LDS Church. None reported, "Not at all active in the LDS Church." Based on these results, the authors confidently describe the majority of this LDS sample as highly religious.

The authors believed that inviting individuals who they knew were LDS would be an effective method of collecting data. Therefore, LDS participants were recruited through announcements distributed nationwide via Facebook inviting them to participate. There were no exclusion criteria for participation in the study. Participants completed the survey online through Qualtrics,

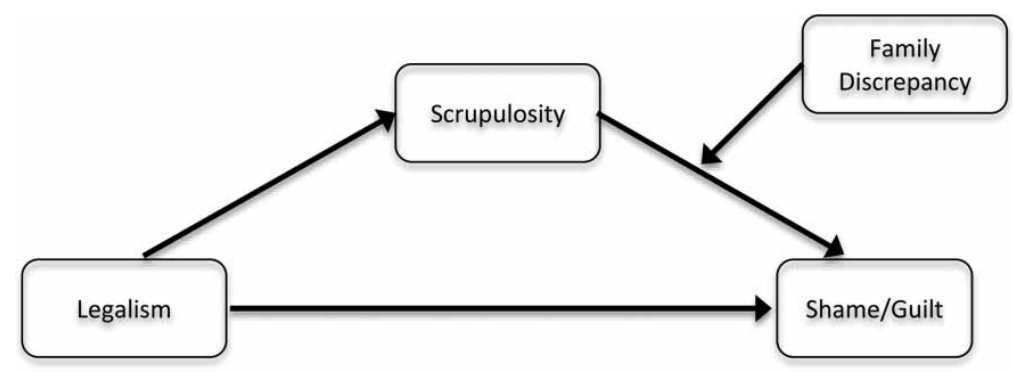

Figure 1. Moderated-mediation model examining the moderating effect of family discrepancy on the mediation of legalism and shame/guilt by scrupulosity. 
receiving a $\$ 10$ gift card as an incentive and compensation for their time. A doctoral student who assisted in the data collection of this study posted the Qualtrics link on her Facebook profile, which contains roughly $80 \%$ LDS individuals. The response rate was tracked through Facebook by asking participants to message back indicating if they had or had not taken the study. That number of those who indicated through Facebook that they had participated in the study corresponded with the Qualtrics number of participants completing the study, resulting in a response rate of $84 \%$.

\section{Instruments}

Religious Commitment Inventory-10 (RCI-10; Worthington et al., 2003). This instrument consists of 10 items and 2 factors: Intrapersonal (cognitive focus) and Interpersonal (behaviour focus) Commitment. For example, "It is important to me to spend periods of time in private religious thought and reflection" is an intrapersonal item; "I enjoy working in the activities of my religious organization" is an interpersonal statement. Participants rated each item on a Likert-type scale: 1 (not at all true of me), 2 (somewhat true of me), 3 (moderately true of me), 4 (mostly true of me), or 5 (totally true of me). Intra- and Interpersonal Religious Commitment were highly correlated, and test-retest reliability over a five-month period was .91 (Worthington et al., 2003). The Cronbach alpha for the RCI-10 was .95 for the intrapersonal items and .89 for the interpersonal items in recent studies with similar samples of LDS people (Allen \& Heppner, 2011; Allen \& Wang, 2014). The Cronbach alpha of the composite RCI-10 scores for the current study was .88.

Family Almost Perfect Scale (FAPS; Wang, 2010). The FAPS is a 17-item self-report measure rated on a Likert scale ranging from 1 (strongly disagree) to 7 (strongly agree). The measure comprises three subscales: Family Standards (FS), Family Order (FO), and Family Discrepancy (FD), but only used FS and FD subscales as they align with our research hypotheses and are relevant for the specific variables targeted for examination. Sample items include "My family has high standards for my performance at work or at school" (FS) and "My best just never seems to be good enough for my family" (FD). Standards and discrepancy are the essential features of adaptive and maladaptive perfectionism and thus are most often examined in research studies (Allen \& Wang, 2014). For the current study, the Cronbach alpha for FS was .89 and for FD was .94.

Penn Inventory of Scrupulosity (PIOS; Abramowitz et al., 2002). The PIOS is a 19-item selfreport measure rated on a Likert scale ranging from 0 (never) to 4 (constantly). It includes two subscales: Fear of Sin (12 items) and Fear of God (7 items). Sample items include "I feel urges to confess sins over and over again" and "I worry I will never have a good relationship with God." The Cronbach alpha was .93 for the composite score of another sample (Abramowitz et al., 2002) and .92 for this study.

Graceful Avoidance of Personal Legalism (GAPL; Watson et al., 2011). The GAPL is a subscale of the larger Richmont Grace Scale (RGS; Watson et al., 2011), designed to measure contrasting assumptions common to Christians: God's grace and favour earned vs. God's grace freely given. It is a four-item self-report measure based on a 5-point Likert-type scale ranging from 1 (strongly disagree) to 5 (strongly agree). Higher scores indicate a stronger belief that one must earn God's grace through works (legalism). Sample items include "I must work hard to experience God's grace and forgiveness" and "The harder I work, the more I earn God's favor." The Cronbach alpha was .61 in the original study (Watson et al., 2011). For this study, the Cronbach alpha was .63. According to DeVellis (2012), an internal consistency between .60 and .65 is undesirable, but not unacceptable. Therefore, given that legalism is inherently a complex concept and thus difficult to measure, the authors found it sufficient and necessary to use this instrument for this LDS sample as it closely examines the concept of legalism and working for God's acceptance and approval, specifically. 
State Shame and Guilt Scale (Marschall, Sanftner, \& Tangney, 1994). To measure shame and guilt, this instrument includes three subscales: Pride (5 items), Shame (5 items), and Guilt (5 items); only Shame and Guilt were used in this study. The items are measured with a Likerttype scale ranging from 1 (not feeling this way at all) to 5 (feeling this way very strongly). Sample items include "I feel humiliated, disgraced" (Shame) and "I feel remorse, regret" (Guilt). The Cronbach alpha was .87 for Shame and .87 for Guilt (Stoeber, Harris, \& Moon, 2007). For this current study, the Cronbach alphas for Shame and Guilt were .84 and .89, respectively.

\section{Results}

After respondents who were not LDS, had failed validity check items, or had missed over $5 \%$ of the items were removed from the data set, 421 participants comprised the sample. As missing data of less than 5\% is considered inconsequential (Schafer, 1999), missing values at the item level were replaced using series means in Statistical Package for the Social Sciences (SPSS) by calculating the mean for that item across participants. The mean, standard deviation, and Cronbach alpha estimates of each variable, along with the correlations among the study variables, are presented in Table 1.

For Hypothesis 1, an independent sample $t$-test was conducted to determine whether study variables varied between genders. The results indicated that LDS women reported significantly higher on religious commitment than LDS men $(t=-2.80, p=.005)$, but men scored significantly higher on scrupulosity $(t=5.27, p<.001)$ and guilt $(t=2.61, p=.009)$ than women. For the remaining study variables, there were no significant differences between men and women. Hypothesis 1 was partially supported in which LDS women endorsed significantly higher levels of religious commitment, but did not report higher guilt and scrupulosity compared to LDS men. The higher guilt among LDS men in this sample is inconsistent with previous research, which found that LDS women scored higher than LDS men on guilt (Richards et al., 1989).

\section{Mediation and moderated-mediation analyses}

We used the SPSS macro PROCESS (Hayes \& Preacher, 2014) to conduct the mediation and moderated-mediation analyses. PROCESS offers bootstrap estimates to calculate bias-corrected confidence intervals (CI) for the mediation and moderated-mediation effects. This bootstrapping method, which has advantages over the causal steps approach (Baron \& Kenny, 1986)

Table 1. Intercorrelations of study variables.

\begin{tabular}{lcccccccrr}
\hline & 1 & 2 & 3 & 4 & 5 & 6 & 7 & $M$ & SD \\
\hline Religious commitment & $\mathbf{. 8 8}$ & & & & & & & 43.17 & 6.01 \\
Legalism & -.02 & $\mathbf{. 6 3}$ & & & & & & 12.14 & 3.30 \\
Scrupulosity & $-.12^{*}$ & $.30^{* * *}$ & $\mathbf{. 9 2}$ & & & & & 46.12 & 11.78 \\
Shame & $-.32^{* *}$ & $.15^{* *}$ & $.42^{* * *}$ & $\mathbf{. 8 4}$ & & & & 7.38 & 3.20 \\
Guilt & $-.20^{* * *}$ & $.17^{* *}$ & $.53^{* * *}$ & $.65^{* * *}$ & $\mathbf{. 9 0}$ & & & 9.07 & 4.15 \\
Family discrepancy & $-.10^{*}$ & $.01^{* *}$ & $.24^{* * *}$ & $.37^{* * *}$ & $.20^{* * *}$ & $\mathbf{. 9 4}$ & & 16.51 & 9.37 \\
Family standards & $.20^{* * *}$ & $.13^{* *}$ & $.20^{* * *}$ & -.01 & $.10^{*}$ & $.20^{* * *}$ & $\mathbf{. 8 8}$ & 35.73 & 6.29 \\
\hline
\end{tabular}

Notes: $N=421$. Cronbach alphas are displayed in bold across the diagonal.

${ }^{*} p<.05$, two-tailed.

$* * p<.01$, two-tailed.

$* * * p<.001$, two-tailed. 
and the Sobel (1982) test, has been recommended as the method of choice for testing indirect effects (Hayes, 2009). The procedure, which involves resampling multiple times and estimating the sampling distribution from all the resamples, enhances estimation accuracy of the indirect effects (Preacher \& Hayes, 2008). In this study, we estimated the mean of $95 \%$ CI of indirect effects derived from 10,000 bootstrap samples. If the upper and lower bounds of the CI do not include zero, then the presence of an indirect effect can be concluded with $95 \%$ CI.

For Hypothesis 2a, we examined the indirect effect of scrupulosity on the association between legalism and shame, while controlling for religious commitment (see Table 2). Bootstrapping results indicated that scrupulosity fully mediated the link between legalism and shame $(95 \%$ CI $(.07, .17)$; indirect effect $=.11, \mathrm{SE}=.02, Z=4.73, p<.001$; total effect $=.14, \mathrm{SE}=.05, t=$ 2.94, $p=.004$; direct effect $=.03, \mathrm{SE}=.04, t=.63, p=.53)$. In other words, the shame that LDS individuals may experience, in response to legalism, is mediated through the fear of sin and God. More specifically, higher levels of legalism are associated with higher levels of scrupulosity, which in turn are associated with higher levels of shame. For Hypothesis $2 b$, we followed the same method to examine the indirect effect of scrupulosity on the relation between legalism and guilt. Bootstrapping estimates indicated that scrupulosity fully mediated the link between legalism and guilt $(95 \% \mathrm{CI}(.12, .28)$; indirect effect $=.19, \mathrm{SE}=.04, Z=5.20, p<.001$; total effect $=.21, \mathrm{SE}=.06, t=3.48, p<.001$; direct effect $=.01, \mathrm{SE}=.06, t=.24, p=.81)$. Similarly, higher levels of legalism are associated with higher levels of scrupulosity, which in turn are associated with higher levels of guilt. Thus, both Hypothesis $2 \mathrm{a}$ and Hypothesis $2 \mathrm{~b}$ were supported.

In Hypothesis 3, we predicted that family discrepancy would moderate the indirect effect of the mediation models. For Hypothesis $3 \mathrm{a}$, we anticipated that family discrepancy would amplify the association between scrupulosity and shame (see Figure 1). Bootstrapping results using PROCESS model 14, presented in Table 3, indicated that the interaction between family discrepancy and scrupulosity in predicting shame was significant $(B=.005, \mathrm{SE}=.001, t=4.16$, $p<.001)$. The link between scrupulosity and shame was stronger with high $(+1 \mathrm{SD})$ family

Table 2. Regression results for mediation: panel A (Legalism $\rightarrow$ Scrupulosity $\rightarrow$ Shame) and panel B (Legalism $\rightarrow$ Scrupulosity $\rightarrow$ Guilt).

\begin{tabular}{|c|c|c|c|c|}
\hline Predictor & $B$ & SE & $t$ & $p$ \\
\hline \multicolumn{5}{|c|}{ Panel A: DV $=$ Shame $\left(R^{2}=.25\right)$} \\
\hline Constant & 8.59 & 1.61 & 5.33 & .000 \\
\hline Scrupulosity & .10 & .01 & 7.43 & .000 \\
\hline Legalism & .03 & .04 & .63 & .528 \\
\hline \multirow[t]{2}{*}{ Religious commitment } & -.15 & .04 & -4.11 & .000 \\
\hline & Effect & Boot SE & \multicolumn{2}{|c|}{$95 \% \mathrm{CI}$} \\
\hline Indirect effect & 0.11 & 0.02 & \multicolumn{2}{|c|}{$[0.07,0.17]$} \\
\hline Predictor & $B$ & $\mathrm{SE}$ & $t$ & $p$ \\
\hline \multicolumn{5}{|c|}{ Panel B: DV $=$ Guilt $\left(R^{2}=.30\right)$} \\
\hline Constant & 4.88 & 1.88 & 2.59 & .010 \\
\hline Scrupulosity & .18 & .02 & 9.76 & .000 \\
\hline Legalism & .01 & .06 & .24 & .811 \\
\hline Religious commitment & -.10 & .04 & -2.60 & .010 \\
\hline & Effect & Boot SE & \multicolumn{2}{|c|}{$95 \% \mathrm{CI}$} \\
\hline Indirect effect & .19 & .04 & \multicolumn{2}{|c|}{$[.12, .28]$} \\
\hline
\end{tabular}

Notes: $N=421$. All $p$ values, two-tailed. $\mathrm{DV}=$ dependent variable and $\mathrm{CI}=$ confidence interval. 
Table 3. Regression results for conditional indirect effect: legalism $\rightarrow$ scrupulosity $\rightarrow$ shame (moderator, family discrepancy; covariate, religious commitment).

\begin{tabular}{lcccc}
\hline Predictor & $B$ & SE & $t$ & $p$ \\
\hline Mediator model (DV = scrupulosity) & & & & \\
$\quad$ Constant & -3.74 & 4.57 & -.82 & .413 \\
$\quad$ Legalism & 1.08 & .17 & 6.18 & .000 \\
$\quad$ Religious commitment & -.22 & .09 & -2.40 & .017 \\
Outcome model (DV = shame) & 12.72 & 1.43 & 8.91 & .000 \\
$\quad$ Constant & .09 & .01 & 7.19 & .000 \\
Scrupulosity & .00 & .04 & -.01 & .996 \\
Legalism & .08 & .02 & 4.97 & .000 \\
Family discrepancy & .000 & .00 & 4.16 & .000 \\
Scrupulosity $\times$ family discrepancy & -.13 & .03 & -3.70 & .000 \\
$\quad$ Religious commitment & Effect & Boot SE & & $95 \% \mathrm{CI}$ \\
Conditional effects at moderator & .05 & .02 & {$[.02, .09]$} \\
\hline SD below & .10 & .02 & {$[.06, .15]$} \\
Mean & .15 & .03 & {$[.09, .21]$} \\
1 SD above & & & \\
\hline
\end{tabular}

Note: $N=421$. All $p$ values, two-tailed. $\mathrm{DV}=$ dependent variable; $\mathrm{CI}=$ confidence interval. For the mediator model $R^{2}$ $=.10$; for the outcome model $R^{2}=.34$.

Table 4. Regression results for conditional indirect effect: legalism $\rightarrow$ scrupulosity $\rightarrow$ guilt (moderator, family discrepancy; covariate, religious commitment).

\begin{tabular}{|c|c|c|c|c|}
\hline Predictor & $B$ & $\mathrm{SE}$ & $t$ & $p$ \\
\hline \multicolumn{5}{|l|}{ Mediator model (DV = scrupulosity) } \\
\hline Constant & -3.74 & 4.57 & -.82 & .413 \\
\hline Legalism & 1.08 & .17 & 6.18 & .000 \\
\hline Religious commitment & -.22 & .09 & -2.40 & .017 \\
\hline \multicolumn{5}{|l|}{ Outcome model (DV = guilt) } \\
\hline Constant & 13.01 & 1.74 & 7.48 & .000 \\
\hline Scrupulosity & .18 & .02 & 9.27 & .000 \\
\hline Legalism & .01 & .06 & .12 & .909 \\
\hline Family discrepancy & .03 & .02 & 1.26 & .209 \\
\hline Scrupulosity $\times$ family discrepancy & .00 & .00 & .66 & .507 \\
\hline Religious Commitment & -.09 & .04 & -2.43 & .016 \\
\hline Conditional effects at moderator & Effect & Boot SE & \multicolumn{2}{|c|}{$95 \% \mathrm{CI}$} \\
\hline $1 \mathrm{SD}$ below & .18 & .04 & \multicolumn{2}{|c|}{$[.10, .27]$} \\
\hline Mean & .19 & .04 & \multicolumn{2}{|c|}{$[.12, .28]$} \\
\hline $1 \mathrm{SD}$ above & .20 & .04 & \multicolumn{2}{|c|}{$[.12, .29]$} \\
\hline
\end{tabular}

Notes: $N=421$. All $p$ values, two-tailed. $\mathrm{DV}=$ dependent variable; $\mathrm{CI}=$ confidence interval. For the mediator model $R^{2}$ $=.10$; for the outcome model $R^{2}=.31$.

discrepancy $(B=.15, \mathrm{SE}=.03)$ than with low $(-1 \mathrm{SD})$ family discrepancy $(B=.05, \mathrm{SE}=.02)$. But for Hypothesis $3 \mathrm{~b}$, bootstrapping results, presented in Table 4 , indicated that the interaction between family discrepancy and scrupulosity in predicting guilt was not significant $(B=.001$, $\mathrm{SE}=.002, t=.66, p=.51)$. In sum, family discrepancy was a significant moderator for association among (legalism $\rightarrow$ scrupulosity $\rightarrow$ shame), but not for that of (legalism $\rightarrow$ scrupulosity $\rightarrow$ guilt). 


\section{Discussion}

\section{Mediation of scrupulosity}

The excessive scrupulous fear of sinful activity and punishment from God mediates the drive to earn God's favour through works resulting in guilt and shame for their imperfection. These results could mean that due to having strong legalistic beliefs, individuals can become overly fearful of making mistakes (committing sin) because these mistakes will prevent them from pleasing God. In other words, the guilt and shame that LDS individuals may experience are mediated through the fear of not being good enough when their relationship with God is based on the need to please God through one's own power, rather than on the reliance and receiving of God's grace. Perhaps therapists could strengthen the coping of highly religious frightened individuals by helping them to recognise God for His love and compassion for all people, including those who make mistakes.

\section{Moderated mediation of family discrepancy on scrupulosity, shame, and guilt}

The moderated-mediation analysis found that family discrepancy intensified the link between scrupulosity and shame, but not between scrupulosity and guilt. These specific results could suggest that an environment with high levels of maladaptive family perfectionism (i.e., family discrepancy) could not only be linked to a more fear-driven pattern of religious living and behaviours, away from a faith-based approach to religiosity (Allen \& Wang, 2014), but also exacerbate the potential shame associated with scrupulosity. Moreover, one's religious concerns may also be influenced by ways the family environment (e.g., family discrepancy) may distort the individual's beliefs or intensify the detrimental effects of scrupulosity. In sum, the family environment in which individuals are raised can have an influence on their religious well-being.

Family discrepancy, however, was not found to intensify the link between scrupulosity and guilt. This suggests that family discrepancy did not strengthen this link, but could suggest that scrupulosity may not have as much negative influence over one's feelings of guilt related to behaviours, but perhaps more maladaptive influence on the way shame is connected to how one feels about his or her character and worth before God. This result seems to be parallel with existing research on how maladaptive perfectionism was found to have a stronger link with the overall self-worth compared to self-efficacy in performance (Suh, Yuen, Wang, Fu, \& Trotter, 2014). In other words, these individuals may experience levels of shame (i.e., disappointment and disapproval) before God and others more intensely than the levels of guilt they perceive over sinful behaviour. One might be led to think that possibly a feeling of guilt could be more easily assuaged through spiritual repentance and improvement of behaviours, but the memory of an offensive act towards God may lead one to feel the lingering effects of shame after the sinful behaviour.

Related to gender differences, religious commitment was found to be higher for women than men, indicating perhaps a tendency for women to be more committed to the LDS Church regarding its doctrine and practices. However, men endorsed higher levels of scrupulosity and guilt compared to women, which could indicate that these LDS men may be more likely to struggle with feelings of fear from God related to sinful activities and punishment, as well as feelings of guilt following behaviours that are perceived as offensive to God. This difference between genders and heightened scrupulosity and guilt could possibly explain men's lower levels of religious commitment compared to women's high commitment as LDS men may not feel devout enough when guilt and fear settle in based on the perception of unfavourable behaviours. A difference between LDS males and females regarding guilt may show a possible shift from past findings (Richards et al., 1989) and this study. 


\section{Practical implications}

Findings from this study suggest practical implications, as well as considerations, when working with highly religious LDS individuals in counselling. Therapists must be aware that family perfectionism is multidimensional, having both positive and negative aspects (Wang, Puri, Slaney, Methikalam, \& Chadha, 2012). Helping LDS members who may be struggling with family perfectionism may begin with differentiating between having high perceived family standards and feeling that their family members are never satisfied with their performances. Having high family standards can be adaptive and healthy both in general and in the context of their faith. LDS religious families may have a goal to strive to reflect God's characteristics through their daily living, but could also remember to consider that humans are vulnerable to shortcomings, and (contrary to legalistic beliefs) may anticipate that through the grace of God they can begin to heal from feelings of shame and guilt. Therefore, effectively coping with a nitpicking message linked to one's family expectations may be a better option rather than lowering one's family standards to decrease the unfavourable consequences of family maladaptive perfectionism. In brief, family discrepancy is maladaptive and should be remedied, but having high family standards is not and ought to be encouraged (Allen \& Wang, 2014).

Examining how one's family discrepancy may be influencing his or her level of scrupulosity, particularly related to shame, is important to consider when understanding the individual's emotional well-being. Therapists could possibly assist potential LDS clients explore their beliefs around being faithful in their religion which could be impacted by their upbringing, distorted by the feeling that they can never be good enough to and for their families. Perhaps assisting them to seek a more accurate understanding of the nature and love of God (i.e., grace) as taught by LDS doctrine could lessen the effects of family discrepancy, scrupulosity, and shame (Allen \& Wang, 2014). While some forms of religious living may lead to psychological difficulties (Exline, Yali, \& Sanderson, 2000), a significant body of research literature shows the positive psychological outcomes of religiosity (Allen \& Heppner, 2011; Allen \& Wang, 2014; Yeh, Arora, \& Wu, 2006; Yeh, Inman, $\mathrm{Kim}, \&$ Okubo, 2006). Hence the factor that is correlated with distress is not religious commitment, but rather strong legalistic beliefs with the distorted focus on never being good enough for the family.

The results of this study could have an influence on helping LDS individuals clarify feelings of guilt and shame that may be associated with a belief in legalism. Particular sensitivity by clergypersons of various faiths towards members who struggle with these issues could create opportunities for communication and connection as they reach out to their distressed church members (Allen \& Hill, 2014; Allen \& Wang, 2014). Providing psycho-educational information and pastoral counselling referrals on issues such as family perfectionism, guilt, shame, and psychological adjustment could help struggling religious individuals more accurately and appropriately redefine their psychological experiences (Allen \& Wang, 2014). This information can be disseminated not only to individuals for self-help, but also to parents to educate them about the powerful influences of being perfectionistically critical on family members and how that can negatively impact them and the overall family system.

\section{Study limitations}

A limitation to this study that should be mentioned is the age range of participating adults. Because the mean age was in the early 20 s, researchers cannot infer generalisability across a range of age groups of LDS members. Factors in this age group such as life stage, development level, and context-appropriate family standards could have influenced or overinflated the results in a direction towards perfectionism and scrupulosity that possibly would not be found in older age groups. For example, typically LDS members in this age group are encouraged to begin considering their family expectations and standards as they marry and begin having children, 
continue and complete their education, and plan for successful careers that will enable them to support their families - all based on LDS family-centred values and standards (Hinckley, 1995). Future studies may include samples of different age groups.

Researchers might also find it beneficial to work with LDS members living in additional regions of the USA and other nations, where varied cultural contexts may affect ideas, beliefs, or perceptions of religious commitment - particularly guilt, shame, and grace of God. In addition, future studies may extend the literature by studying religious commitment, guilt, shame, scrupulosity, and family perfectionism with other religious groups in the USA and other countries. This study was cross-sectional, thus a causal relationship cannot be determined. Future studies may incorporate an experimental design to better understand the causal effects as well as further this line of research by using qualitative methods to better explore the underlying mechanism among these variables.

\section{Conclusion}

Research regarding psychological issues with LDS religious people warrants additional attention. The results have increased the knowledge base regarding (mostly younger) LDS individuals and families, regarding how family perfectionism, scrupulosity, and legalism may influence or how they are associated with guilt and shame, offering a broader understanding of LDS Church members' psychological adjustment. Findings from this study may also have implications for families from other religious groups both in the USA and in other countries - a possible next step in advancing the knowledge base.

\section{References}

Abramowitz, J. S., Huppert, J. D., Cohen, A. B., Tolin, D. F., \& Cahill, S. P. (2002). Religious obsessions and compulsions in a non-clinical sample: The Penn Inventory of Scrupulosity (PIOS). Behaviour Research and Therapy, 40(7), 825-838. doi:10.1016/S0005-7967(01)00070-5

Allen, G. E. K., \& Heppner, P. P. (2011). Religiosity, coping, and psychological well-being among LatterDay Saint polynesians in the US. Asian American Journal of Psychology, 2(1), 13-24. doi:10.1037/ a0023266

Allen, G. E. K., \& Hill, C. (2014). Exploring perceived attitudes of counseling between LDS religious leaders and mental health therapists. Religion and Psychotherapy, 36, 71-82.

Allen, G. E. K., \& Wang, K. (2014). Examining aspects of religiosity, perfectionism, scrupulosity, and wellbeing among LDS individuals. Psychology of Religion and Spirituality, 6, 257-264. doi:10.1037/ a0035197

Antony, M. M., Downie, F., \& Swinson, R. P. (1998). Diagnostic issues and epidemiology in obsessive-compulsive disorder. In R. P. Swinson, M. M. Antony, S. S. Rachman, \& M. A. Richter (Eds.), Obsessivecompulsive disorder: Theory, research, and treatment (pp. 3-32). New York, NY: The Guilford Press.

Antony, M. M., Downie, F., \& Swinson, R. P. (1998). Obsessive compulsive disorder: Theory, research and treatment (pp. 397-425). New York, NY: The Guilford Press.

Baron, R. M., \& Kenny, D. A. (1986). The moderator-mediator variable distinction in social psychological research: Conceptual, strategic, and statistical considerations. Journal of Personality and Social Psychology, 51(6), 1173-1182. doi:10.1037/0022-3514.51.6.1173

Bassett, R. L. (2013). An empirical consideration of grace and legalism within Christian experience. Journal of Psychology \& Christianity, 32(1), 43.

Cefalu, P. (2010). The doubting disease: Religious scrupulosity and obsessive-compulsive disorder in historical context. Journal of Medical Humanities, 31, 111-125. doi:10.1007/s10912-010-9107-3

Ciarrocchi, J. W. (1995). The doubting disease: Help for scrupulosity and religious compulsions. Mahwah, NJ: Paulist Press.

DeVellis, R. F. (2012). Scale development: Theory and applications (3rd ed.). Thousand Oaks, CA: Sage.

Exline, J. J., Yali, A. M., \& Sanderson, W. C. (2000). Guilt, discord, and alienation: The role of religious strain in depression and suicidality. Journal of Clinical Psychology, 56(12), 1481-1496. doi:10.1002/ 1097-4679(200012)56:12<1481::AID-1>3.0.CO;2-A 
Fedewa, B. A., Burns, L. R., \& Gomez, A. A. (2005). Positive and negative perfectionism and the shame/ guilt distinction: Adaptive and maladaptive characteristics. Personality and Individual Differences, 38 (7), 1609-1619. doi:10.1016/j.paid.2004.09.026

Fergus, T. A., \& Valentiner, D. P. (2012). Terror management theory and scrupulosity: An experimental investigation. Journal of Obsessive-Compulsive and Related Disorders, 1(2), 104-111. doi:10.1016/j. jocrd.2012.01.003

Foa, E. B., Abramowitz, J. S., Franklin, M. E., \& Kozak, M. J. (1999). Feared consequences, fixity of belief, and treatment outcome in patients with obsessive-compulsive disorder. Behavior Therapy, 30(4), 717 724. doi:10.1016/S0005-7894(99)80035-5

Hayes, A. F. (2009). Beyond Baron and Kenny: Statistical mediation analysis in the new millennium. Communication Monographs, 76(4), 408-420. doi:10.1080/03637750903310360

Hayes, A. F., \& Preacher, K. J. (2014). Statistical mediation analysis with a multicategorical independent variable. British Journal of Mathematical and Statistical Psychology, 67(3), 451-470.

Hinckley, G. B. (1995, September 23). The family: A proclamation to the world. The Church of Jesus Christ of Latter-Day Saints. Proclamation read by President Gordon B. Hinckley as part of his message at the General Relief Society Meeting, Salt Lake City, Utah.

Konstam, V., Chernoff, M., \& Deveney, S. (2001). Toward forgiveness: The role of shame, guilt anger, and empathy. Counseling and Values, 46, 26-39. doi:10.1002/j.2161-007X.2001.tb00204.x

Marschall, D., Sanftner, J., \& Tangney, J. P. (1994). The state shame and guilt scale. Fairfax, VA: George Mason University.

Miller, C. H., \& Hedges, D. W. (2008). Scrupulosity disorder: An overview and introductory analysis. Journal of Anxiety Disorders, 22(6), 1042-1058. doi:10.1016/j.janxdis.2007.11.004

Nelson, E. A., Abramowitz, J. S., Whiteside, S. P., \& Deacon, B. J. (2006). Scrupulosity in patients with obsessive-compulsive disorder: Relationship to clinical and cognitive phenomena. Journal of Anxiety Disorders, 20(8), 1071-1086. doi:10.1016/j.janxdis.2006.02.001

Ortega, N. E., Wang, K. T., Slaney, R. B., Hayes, J. A., \& Morales, A. (2014). Personal and familial aspects of perfectionism in Latino/a students. The Counseling Psychologist, 42, 406-427. doi:10.1177/ 0011000012473166

Post, B. C., \& Wade, N. G. (2009). Religion and spirituality in psychotherapy: A practice-friendly review of research. Journal of Clinical Psychology, 65(2), 131-146. doi:10.1002/jclp.20563

Preacher, K. J., \& Hayes, A. F. (2008). Asymptotic and resampling strategies for assessing and comparing indirect effects in multiple mediator models. Behavior Research Methods, 40(3), 879-891. doi:10.3758/ BRM.40.3.879

Rice, K. G., \& Slaney, R. B. (2002). Clusters of perfectionists: Two studies of emotional adjustment and academic achievement. Measurement and Evaluation in Counseling and Development, 35(1), 35-48.

Richards, P. S., \& Bergin, A. E. (2005). A spiritual strategy for counseling and psychotherapy. Washington, DC: American Psychological Association. doi:10.1037/10241-000

Richards, P. S., Owen, L., \& Stein, S. (1993). A religiously oriented group counseling intervention for selfdefeating perfectionism: A pilot study. Counseling and Values, 37(2), 96-104. doi:10.1002/j.2161007X.1993.tb00801.x

Richards, P. S., Smith, S. A., \& Davis, L. F. (1989). Healthy and unhealthy forms of religiousness manifested by psychotherapy clients: An empirical investigation. Journal of Research in Personality, 23(4), 506524. doi:10.1016/0092-6566(89)90017-2

Schafer, J. L. (1999). Multiple imputation: A primer. Statistical Methods in Medical Research, 8(1), 3-15. doi: $10.1191 / 096228099671525676$

Sobel, M. E. (1982). Asymptotic confidence intervals for indirect effects in structural equation models. Sociological Methodology, 13(1982), 290-312. doi:10.2307/270723

Stoeber, J., Harris, R. A., \& Moon, P. S. (2007). Perfectionism and the experience of pride, shame, and guilt: Comparing healthy perfectionists, unhealthy perfectionists, and non-perfectionists. Personality and Individual Differences, 43(1), 131-141. doi:10.1016/j.paid.2006.11.012

Stoeber, J., \& Otto, K. (2006). Positive conceptions of perfectionism: Approaches, evidence, challenges. Personality and Social Psychology Review, 10, 295-319. doi:10.1207/s15327957pspr1004 2

Suh, H. N., Yuen, M., Wang, K. T., Fu, C. C., \& Trotter, R. H. (2014). Comparing perfectionist types on family environment and well-being among Hong Kong adolescents. Personality and Individual Differences, 70, 111-116. doi:10.1016/j.paid.2014.06.023

Wang, K. T. (2010). The Family Almost Perfect Scale: Development, psychometric properties, and comparing Asian and European Americans. Asian American Journal of Psychology, 1(3), 186-199. doi:10. $1037 / \mathrm{a} 0020732$ 
Wang, K. T., Puri, R., Slaney, R. B., Methikalam, B., \& Chadha, N. (2012). Cultural validity of perfectionism among Indian students: Examining personal and family aspects through a collectivistic perspective. Measurement and Evaluation in Counseling and Development, 45, 32-48. doi:10.1177/0748175611423109

Wang, K. T., Wong, Y. J., \& Fu, C. C. (2013). Moderation effects of perfectionism and discrimination on interpersonal factors and suicide ideation. Journal of Counseling Psychology, 60, 367-378. doi:10. $1037 / \mathrm{a} 0032551$

Watson, P. J., Chen, Z., \& Sisemore, T. A. (2011). Grace and Christian psychology - Part 2: Psychometric refinements and relationships with self-compassion, depression, beliefs about sin, and religious orientation. Edification: The Transdisciplinary Journal of Christian Psychology, 4, 64-72.

Worthington, E. L.Jr, Wade, N. G., Hight, T. L., Ripley, J. S., McCullough, M. E., Berry, J. W., \& O'Connor, L. (2003). The Religious Commitment Inventory-10: Development, refinement, and validation of a brief scale for research and counseling. Journal of Counseling Psychology, 50(1), 84-96. doi:10.1037/00220167.50.1.84

Yeh, C. J., Arora, A. K., \& Wu, K. A. (2006). A new theoretical model of collectivistic coping. In P. T. P. Wong \& C. J. Wong (Eds.), Handbook of multicultural perspectives on stress and coping (pp. 55-72). New York, NY: Springer.

Yeh, C. J., Inman, A. C., Kim, A. B., \& Okubo, Y. (2006). Asian American families' collectivistic coping strategies in response to 9/11. Cultural Diversity and Ethnic Minority Psychology, 12(1), 134-148. doi:10.1037/1099-9809.12.1.134 